\title{
Correlation Between Change in Psoriasis Area and Severity Index and Dermatology Life Quality Index in Patients with Psoriasis: Pooled Analysis from Four Phase 3 Clinical Trials of Secukinumab
}

Katherine Houghton · Dhaval Patil · Braulio Gomez · Steven R. Feldman (D)

Received: April 20, 2021 / Accepted: May 28, 2021 / Published online: June 10, 2021

(C) The Author(s) 2021

\begin{abstract}
Introduction: Patients with psoriasis (PsO) experience impaired health-related quality of life due to physical and psychosocial burdens. The objective of this study was to assess the correlation between change in Psoriasis Area and Severity Index (PASI) score and selected Dermatology Life Quality Index (DLQI) domain scores in patients with moderate-to-severe PsO and those with $\mathrm{PsO}$ and comorbid psoriatic arthritis (PsA).

Methods: This post hoc analysis of four phase 3 clinical trials included patients with moderateto-severe $\mathrm{PsO}$ randomized to secukinumab $150 / 300 \mathrm{mg}$, etanercept, or placebo. Pairwise latent growth models were applied to assess the longitudinal correlation between change in PASI scores and changes in three DLQI domain scores (daily activities, leisure activities, and symptoms/feelings). The initial (baseline to week 12) and sustained (week $>12$ to week 52)
\end{abstract}

K. Houghton

RTI Health Solutions, Manchester, UK

D. Patil · B. Gomez

Novartis Pharmaceuticals Corporation, East

Hanover, NJ, USA

S. R. Feldman ( $\square)$

Wake Forest Baptist Medical Center, Winston-

Salem, NC, USA

e-mail: sfeldman@wakehealth.edu treatment exposures were analysed by population type (total, PsO only, and PsO with comorbid PsA) and treatment arm (secukinumab, etanercept, or placebo).

Results: Among the total population $(N=2401)$, PASI change was positively correlated with change in each assessed DLQI domain; correlations were weak to moderate over the initial treatment exposure period $(\beta$ range, $0.20-0.29$; all $P<0.001$ ) and moderate to strong over the sustained exposure period ( $\beta$ range, 0.63-0.69; all $P<0.001$ ). Similar trends were observed regardless of the presence of comorbid PsA. These relationships were confirmed among patients treated with secukinumab, etanercept, or placebo.

Conclusions: Improvements in PASI scores were directly moderately related to improvements in DLQI domain scores from initiation of treatment and extended over time, regardless of presence of comorbid PsA or treatment received.

Clinical Trial Registration: ERASURE (NCT01365455), FIXTURE (NCT01358578), FEATURE (NCT01555125), and JUNCTURE (NCT01636687).

Keywords: Psoriasis; Quality of life; Clinical outcomes 


\section{Key Summary Points}

Patients with psoriasis experience decreased quality of life (QoL) due to the physical and psychological burdens associated with skin symptoms.

However, limited data exist on the extent to which changes in clinical outcomes correlate with changes in dermatologyspecific QoL.

This study demonstrated correlations of improvements in Psoriasis Area and Severity Index with improvements in Dermatology Life Quality Index in patients with moderate-to-severe psoriasis, regardless of comorbid psoriatic arthritis or treatment.

This work highlights the moderate relationship between achieving skin clearance and improving QoL, demonstrating the importance of improving skin clearance in creating a positive impact on disease-specific QoL.

\section{DIGITAL FEATURES}

This article is published with digital features, including a summary slide, to facilitate understanding of the article. To view digital features for this article go to https://doi.org/10.6084/ m9.figshare.14686692.

\section{INTRODUCTION}

Psoriasis (PsO) is a chronic, systemic, immunemediated inflammatory skin disease characterized by key clinical symptoms, including skin itching, scaling, and pain, that affects approximately 7.4 million people in the USA, with an estimated prevalence of $2-4 \%[1,2]$. Approximately $20-30 \%$ of patients with PsO have concurrent psoriatic arthritis (PsA), which can lead to permanent joint damage and loss of functionality $[3,4]$. Furthermore, $\mathrm{PsO}$ is associated with a multitude of other comorbidities, including hypertension, hyperlipidaemia, cardiovascular disease, metabolic disease, inflammatory arthritis, obesity, malignancy, inflammatory bowel disease, anxiety, and depression, which can complicate disease management $[5,6]$. Patients with PsO experience decreased health-related quality of life (HRQoL) due to the physical and psychological burdens of the disease [7].

The mainstay treatment options for PsO are phototherapy, topical medications, and systemic therapies. The American Academy of Dermatology and National Psoriasis Foundation have recommended biologic therapies as viable treatment options for PsO [8]. Currently, the US Food and Drug Administration-approved biologic treatments are the tumour necrosis factor inhibitors adalimumab, certolizumab pegol, etanercept, and infliximab, the interleukin (IL)17 inhibitors secukinumab, ixekizumab, and brodalumab, the IL-12/23 inhibitor ustekinumab, and the IL-23 inhibitors guselkumab, tildrakizumab, and risankizumab.

Biologic treatment can result in skin clearance and better QoL [9]. Measures of skin clearance and HRQoL are moderately correlated on the basis of assessments at single time points [10]. However, the strength of the relationship over time (across multiple time points) is undocumented. Thus, knowledge is lacking regarding whether improvements in skin clearance are directly associated with greater improvement in a disease-specific QoL [11]. Moreover, although greater skin clearance is associated with greater QoL [11], it is unknown whether a relationship between the two continues to exist once a certain threshold of skin clearance is reached. In other words, whether patients continue to report an improved and stable level of QoL once they have achieved and are maintaining a certain level of skin clearance. Furthermore, the effect of comorbid PsA on these relationships was not documented until now; thus, it is undocumented whether improving skin clearance will be associated with the same level of improvement in dermatologyspecific QoL for patients who have comorbid PsA versus those who do not. 
This exploratory, descriptive pooled analysis used clinical trial data to assess the correlation between the longitudinal change in skin clearance (as assessed by the Psoriasis Area and Severity Index [PASI]) and HRQoL (as assessed by the daily activities, leisure activities, and symptoms and feelings domains of the Dermatology Life Quality Index [DLQI]) among patients with moderate-to-severe $\mathrm{PsO}$, with or without comorbid PsA, receiving secukinumab, etanercept, or placebo. We focus on these three DLQI domains, as they have been previously identified as having the most relevance to patient experience and QoL [12].

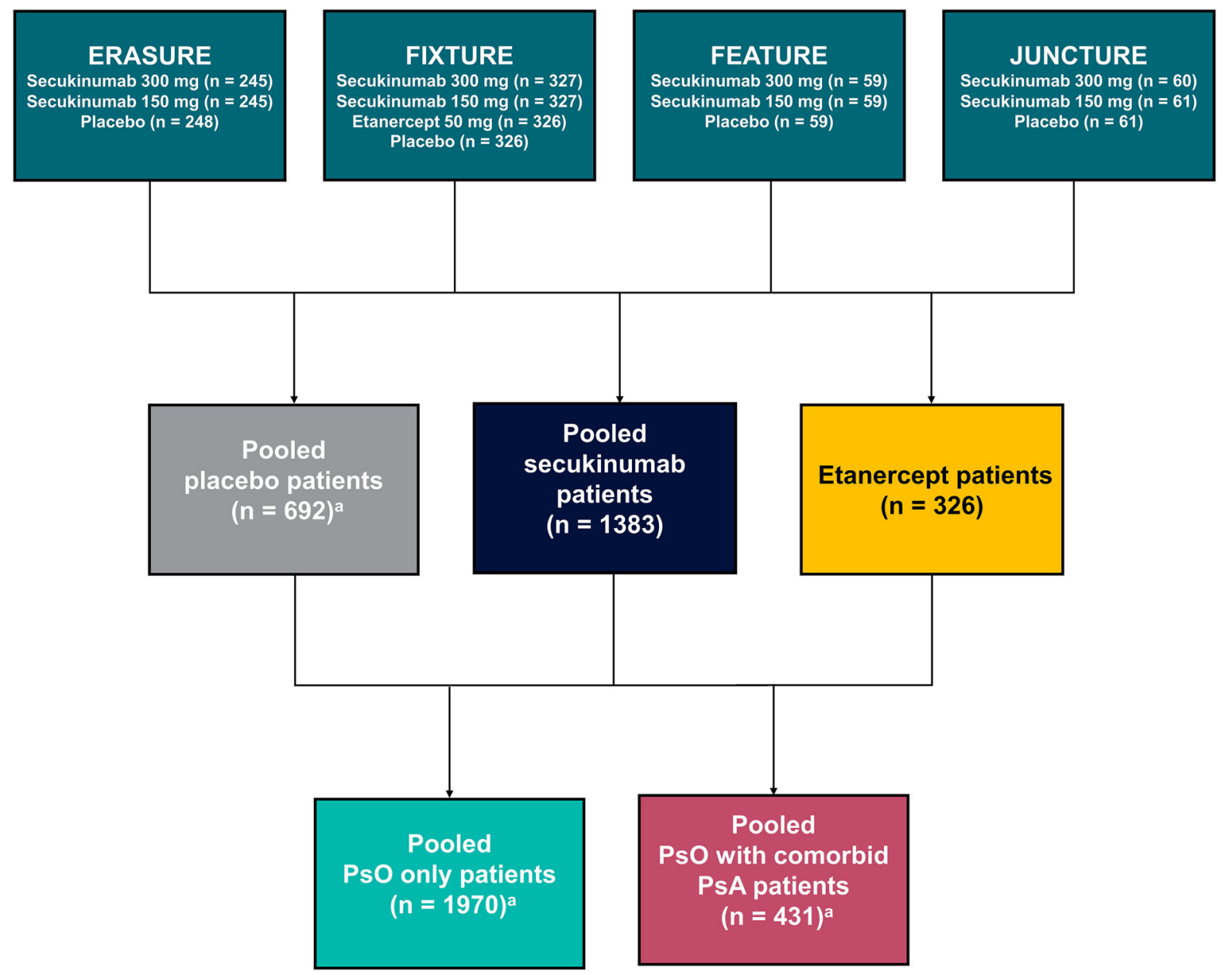

Fig. 1 Study design. $P s A$ psoriatic arthritis, $P_{s} O$ psoriasis. ${ }^{2}$ Number of patients who had Psoriasis Area and Severity Index and Dermatology Life Quality Index data available

\section{METHODS}

\section{Patient Population}

This exploratory post hoc analysis of four phase 3 clinical trials (ERASURE [NCT01365455], FIXTURE [NCT01358578], FEATURE [NCT01555125], and JUNCTURE [NCT01636687]) included patients with moderate-to-severe PsO randomized to secukinumab 150 or $300 \mathrm{mg}$, etanercept, or placebo (Fig. 1) [13-15]. The previously conducted individual study protocols were approved by institutional review boards or ethics committees at all investigational sites. These studies were conducted in accordance with the ethical principles

ecukinumab $300 \mathrm{mg}(\mathrm{n}=327)$

Ukinumab $150 \mathrm{mg}(n=327)$

nercept $50 \mathrm{mg}(n=326)$

Secukinumab $300 \mathrm{mg}(\mathrm{n}=59)$

ukinumab $150 \mathrm{mg}(n=59)$ Placebo $(n=59)$

Secukinumab $300 \mathrm{mg}(n=60$ Placebo $(n=61)$ 
of the Declaration of Helsinki, and all US sites maintained compliance with Health Insurance Portability and Accountability Act regulations. All study subjects were required to provide written consent prior to participating.

\section{Study Variables and Data Analysis}

Demographic characteristics (age, sex, and race), treatment history, clinical characteristics (time since PsO diagnosis, concurrent PsA, and time since PsA diagnosis), and HRQoL (DLQI daily activities, leisure activities, and symptoms/feelings) were examined at baseline for patients stratified by disease cohort (total, PsO only, and PsO with comorbid PsA) and by treatment arm (secukinumab, etanercept, or placebo).

PASI scores were available at baseline and weeks $1,2,3,4$, and every 4 weeks until week 52, and DLQI scores were collected at baseline and weeks $4,8,12,24,36$, and 52 . The DLQI comprises 10 items designed to assess how much skin disease impacts quality of life across six domains (symptoms and feelings, daily activities, leisure, work and school, personal relationships, and treatment), with each item scored from 0 ("not at all") to 3 ("very much") [16]. PASI and DLQI were analysed using latent growth models, which estimate the overall trend of change (growth trajectory) for each individual patient across all time points simultaneously. For each patient, the growth trajectory is estimated; the mean of the individual growth trajectories is the overall change for the treatment arm. Pairwise models were applied to assess the correlation between change in PASI scores (range, 0-72) and changes in each of the three selected DLQI domains (daily activities [items: "over the last week, how much has your skin interfered with you going shopping or looking after your home or garden?" and "over the last week, how much has your skin influenced the clothes you wear?"], leisure activities [items: "over the last week, how much has your skin affected any social or leisure activities?" and "over the last week, how much has your skin made it difficult for you to do any sport?"], and symptoms/feelings [items: "over the last week, how itchy, sore, painful, or stinging has your skin been?" and "over the last week, how embarrassed or self conscious have you been because of your skin?"]; range, 0-6 for each domain). These three DLQI domains have been previously identified as having the most relevance to patient experience and QoL [12]; therefore, our study focuses on correlation of these domains with PASI. The models controlled for known sources of heterogeneity, including previous exposure to biologic therapy, presence of PsA at baseline (for analyses conducted using the total sample and by treatment arm), weight $(<80 \mathrm{~kg}$ or $\geq 80 \mathrm{~kg})$, and smoking history [17-21]. The initial placebocontrolled (baseline to week 12) and sustained re-randomized (week $>12$ to week 52) treatment exposures were assessed. For facilitating assessment of whether the correlations varied as a function of comorbid PsA or treatment received, results of the model are provided as standardized $\beta$ coefficients, indicating that a 1-unit incremental change in PASI score will result in a change in a standardized value on the DLQI at the reported value. Interpretation of the $\beta$ coefficients is the same as correlation coefficients: $0.00-0.19$ is regarded as very weak, $0.20-0.39$ as weak, $0.40-0.59$ as moderate, $0.60-0.79$ as strong, and $0.80-1.00$ as very strong [22]. Subgroup analyses assessing correlations between changes in PASI and DLQI scores were separately analysed by disease cohort (total, PsO only, and PsO with comorbid PsA) and by treatment arm (secukinumab, etanercept, or placebo).

\section{RESULTS}

\section{Patient Demographics and Clinical Characteristics}

Of the 2401 total patients, $1970(82.0 \%)$ were diagnosed with only $\mathrm{PsO}, 431$ (18.0\%) had comorbid PsA with PsO, 1383 (57.6\%) received secukinumab, $326(13.6 \%)$ received etanercept, and $692(28.8 \%)$ received placebo (Table 1). Overall, the mean (SD) age was 44.5 (13.2) years, $69.9 \%$ were male, $72.1 \%$ were White, and mean (SD) time since first diagnosis of PsO was 
Table 1 Baseline characteristics stratified by disease cohort and treatment ${ }^{\mathrm{a}}$

\begin{tabular}{|c|c|c|c|c|c|c|}
\hline Characteristic & $\begin{array}{l}\text { All patients } \\
(N=2401)\end{array}$ & $\begin{array}{l}\text { PsO only } \\
(n=1970)\end{array}$ & $\begin{array}{l}\text { PsO with } \\
\text { comorbid PsA } \\
(n=431)\end{array}$ & $\begin{array}{l}\text { Secukinumab } \\
(n=1383)\end{array}$ & $\begin{array}{l}\text { Etanercept } \\
(n=326)\end{array}$ & $\begin{array}{l}\text { Placebo } \\
(n=692)\end{array}$ \\
\hline Age, mean (SD), years & $44.5(13.2)$ & $44.0(13.3)$ & $47.2(12.3)$ & $44.8(13.4)$ & $42.8(13.0)$ & $\begin{array}{l}44.8 \\
(13.0)\end{array}$ \\
\hline Missing, $n(\%)$ & $435(18.1)$ & $359(18.2)$ & $76(17.6)$ & $249(18.0)$ & $73(22.39)$ & $\begin{array}{l}113 \\
(16.33)\end{array}$ \\
\hline Male, $n(\%)$ & $1678(69.9)$ & $\begin{array}{l}1427 \\
(72.4)\end{array}$ & $251(58.2)$ & $962(69.6)$ & $232(71.2)$ & $\begin{array}{l}484 \\
(69.9)\end{array}$ \\
\hline \multicolumn{7}{|l|}{ Race, $n(\%)$} \\
\hline Asian & $453(18.9)$ & $404(20.5)$ & $49(11.4)$ & $25(18.7)$ & $74(22.7)$ & $\begin{array}{l}121 \\
(17.5)\end{array}$ \\
\hline Black & $35(1.5)$ & $32(1.6)$ & $3(0.7)$ & $22(1.6)$ & 0 & $13(1.9)$ \\
\hline White & $1732(72.1)$ & $\begin{array}{l}1370 \\
(69.5)\end{array}$ & $362(84.0)$ & $1004(72.6)$ & $219(67.2)$ & $\begin{array}{l}509 \\
(73.6)\end{array}$ \\
\hline Native American & $117(4.9)$ & $109(5.5)$ & $8(1.9)$ & $62(4.5)$ & $27(8.3)$ & $28(4.0)$ \\
\hline Other & $51(2.1)$ & $45(2.3)$ & $6(1.4)$ & $29(2.1)$ & $4(1.2)$ & $18(2.6)$ \\
\hline Pacific Islander & $7(0.3)$ & $4(0.2)$ & $3(0.7)$ & $5(0.4)$ & $1(0.3)$ & $1(0.1)$ \\
\hline Unknown & $6(0.3)$ & $6(0.3)$ & 0 & $3(0.2)$ & $1(0.3)$ & $2(0.3)$ \\
\hline $\begin{array}{l}\text { Time since first diagnosis of } \\
\text { psoriasis, mean (SD), years }\end{array}$ & $17.4(12.2)$ & $16.4(11.8)$ & $21.5(13.3)$ & $17.5(12.3)$ & $16.5(12.0)$ & $\begin{array}{l}17.0 \\
\quad(12.2)\end{array}$ \\
\hline \multicolumn{7}{|l|}{ Diagnosis of PsA } \\
\hline Yes, $n(\%)$ & $431(18.0)$ & - & $431(100.0)$ & $250(18.1)$ & $44(13.5)$ & $\begin{array}{l}137 \\
(19.8)\end{array}$ \\
\hline $\begin{array}{l}\text { Time since first diagnosis } \\
\text { of PsA, mean (SD), years }\end{array}$ & $8.6(8.8)$ & - & $8.6(8.8)$ & $7.7(7.9)$ & $9.5(11.6)$ & $9.9(9.0)$ \\
\hline \multicolumn{7}{|l|}{ Prior therapy, $n(\%)$} \\
\hline Systemic & $1520(63.3)$ & $\begin{array}{l}1204 \\
(61.1)\end{array}$ & $316(73.3)$ & $886(64.1)$ & $214(65.6)$ & $\begin{array}{l}420 \\
(60.7)\end{array}$ \\
\hline Biologic & $501(20.8)$ & $358(18.2)$ & $143(33.2)$ & $308(22.3)$ & $45(13.8)$ & $\begin{array}{l}148 \\
(21.4)\end{array}$ \\
\hline $\begin{array}{l}\text { Baseline PASI scores, mean } \\
\quad(\mathrm{SD})\end{array}$ & $22.7(9.7)$ & $22.8(9.8)$ & $22.3(9.3)$ & $22.7(9.7)$ & $23.2(9.8)$ & $22.5(9.7)$ \\
\hline \multicolumn{7}{|c|}{ Baseline DLQI domain scores (0-6), mean (SD) } \\
\hline Daily activities & $2.77(1.79)$ & $2.71(1.77)$ & $3.08(1.86)$ & $2.80(1.79)$ & $2.79(1.80)$ & $\begin{array}{l}2.83 \\
(1.78)\end{array}$ \\
\hline
\end{tabular}


Table 1 continued

\begin{tabular}{lcclccc}
\hline Characteristic & $\begin{array}{l}\text { All patients } \\
(\boldsymbol{N}=\mathbf{2 4 0 1})\end{array}$ & $\begin{array}{l}\text { PsO only } \\
(\boldsymbol{n}=\mathbf{1 9 7 0})\end{array}$ & $\begin{array}{l}\text { PsO with } \\
\text { comorbid PsA } \\
(\boldsymbol{n}=\mathbf{4 3 1})\end{array}$ & $\begin{array}{l}\text { Secukinumab } \\
(\boldsymbol{n}=\mathbf{1 3 8 3})\end{array}$ & $\begin{array}{l}\text { Etanercept } \\
(\boldsymbol{n}=\mathbf{3 2 6})\end{array}$ & $\begin{array}{l}\text { Placebo } \\
(\boldsymbol{n}=\mathbf{6 9 2})\end{array}$ \\
\hline Leisure activities & $2.42(1.92)$ & $2.37(1.88)$ & $2.66(2.06)$ & $2.45(1.92)$ & $2.58(1.94)$ & $\begin{array}{c}2.30 \\
(1.91)\end{array}$ \\
Symptoms and feelings & $3.79(1.51)$ & $3.73(1.50)$ & $4.05(1.54)$ & $3.85(1.50)$ & $3.67(1.58)$ & $\begin{array}{c}3.72 \\
(1.52)\end{array}$ \\
\hline
\end{tabular}

$D L Q I$ Dermatology Life Quality Index, $P A S I$ Psoriasis Area and Severity Index, $P s A$ psoriatic arthritis, $P s O$ psoriasis

${ }^{a}$ Based on available data

17.4 (12.2) years. Additionally, 63.3\% had received prior systemic therapy and $20.8 \%$ had received prior biologics. Compared with patients with PsO only, patients with comorbid PsA were more likely to be female $(41.8 \%$ vs $27.6 \%)$, had a longer time since first diagnosis of $\mathrm{PsO}$ (21.5 vs 16.4 years), and were more likely to be biologic experienced $(33.2 \%$ vs $18.2 \%)$. Baseline characteristics were similar across treatment cohorts, and baseline PASI and DLQI scores in all three domains were similar across cohorts (i.e. by disease and treatment), except patients with comorbid PsA had an overall higher QoL burden as reflected by higher DLQI scores than patients without PsA.

\section{Correlation of PASI and DLQI}

Among the total population, PASI change was positively correlated with change in each assessed DLQI domain; correlations were weak to moderate over the initial treatment exposure period ( $\beta$ range, $0.20-0.29$; all $P<0.001$; Fig. 2 a) and moderate to strong over the sustained exposure period ( $\beta$ range, 0.63-0.69; all $P<0.001)$. Similar trends were observed regardless of the absence (initial treatment: $\beta$ range, 0.17-0.29; all $P<0.001$; sustained exposure: $\beta$ range, $0.61-0.68$; all $P<0.001$; Fig. $2 b$ ) or presence of comorbid PsA (initial treatment: $\beta$ range, $0.24-0.38 ; P=0.004$ to 0.094 ; sustained exposure: $\beta$ range, $0.60-0.72$; all $P<0.001$;
Fig. 2c). These relationships were confirmed among patients treated with secukinumab (initial treatment: $\beta$ range, $0.23-0.38$; all $P<0.001$; sustained exposure: $\beta$ range, $0.43-0.50$; all $P<0.001$; Fig. 3a), etanercept (initial treatment: $\beta$ range, $0.07-0.29 ; P=0.003$ to 0.400 ; sustained exposure: $\beta$ range, $0.45-0.55$; all $P<0.001$; Fig. $3 b$ ), or placebo (initial treatment: $\beta$ range, $0.31-0.42 ; P<0.001$ to 0.550 ; sustained exposure: $\beta$ range, 0.37-0.45; all $P<0.001$; Fig. 3c), although the strength of relationship varied by treatment.

\section{DISCUSSION}

With a longitudinal modelling approach, the associations between changes in skin clearance and changes in HRQoL were assessed among patients with moderate-to-severe $\mathrm{PsO}$ enrolled in phase 3 clinical trials. Further, the extent to which these relationships differed as a function of comorbid PsA or type of treatment received was examined. Pairwise latent growth models were applied to clinician-reported and patientreported data from four clinical trials. The models identified statistically significant moderate positive correlations between changes in skin clearance (as measured by PASI) and changes in HRQoL (as measured by the daily activities, work activities, and symptoms/feelings domains of the DLQI). Thus, as patient levels of skin clearance improved, HRQoL also 

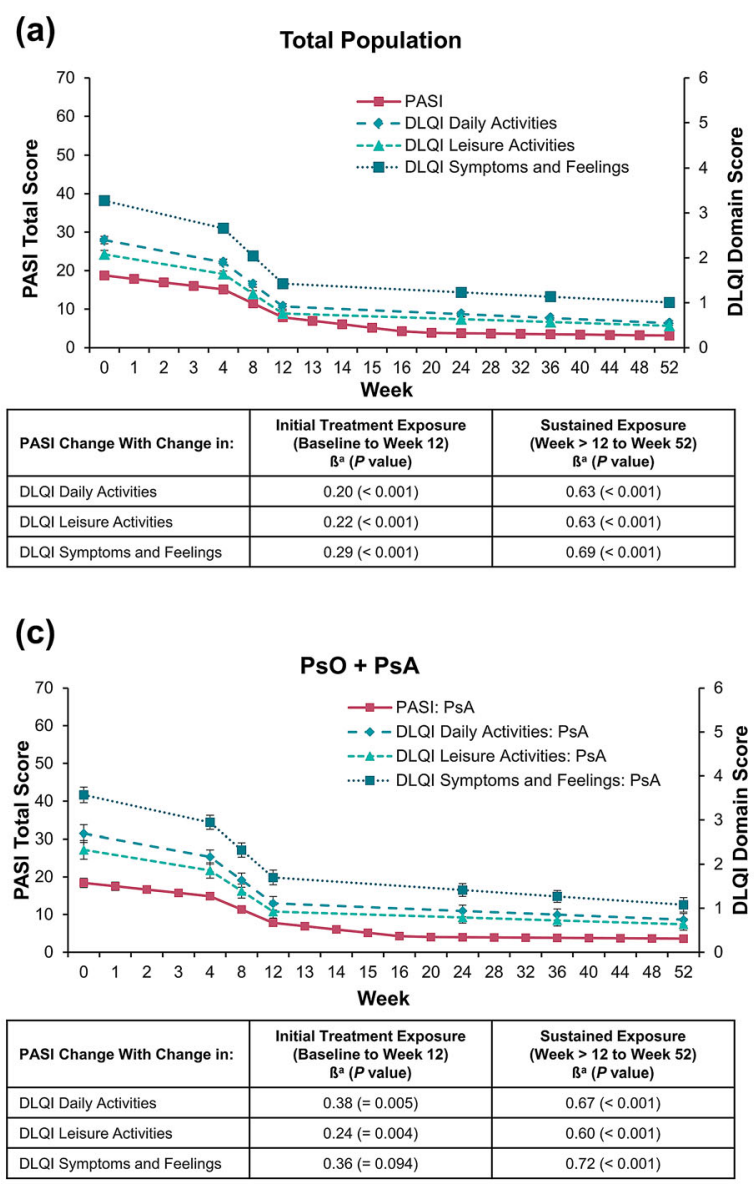

Fig. 2 Correlation of change in PASI and DLQI domains in a all patients, $\mathbf{b}$ patients with $\mathrm{PsO}$ only, and $\mathbf{c}$ patients with $\mathrm{PsO}$ and comorbid PsA. DLQI, Dermatology Life Quality Index; PASI, Psoriasis Area and Severity Index; PsA, psoriatic arthritis; $\mathrm{PsO}$, psoriasis. ${ }^{\mathrm{a}} \beta$ (standardized residual covariance: i.e. the correlation between the slopes

improved (and vice versa). Likewise, as patient levels of skin clearance were maintained, HRQoL was maintained. These relationships were replicated among patients with comorbid PsA and among patients receiving active treatment (secukinumab or etanercept) or placebo.

During the period in which skin clearance improved, there was a weak-to-moderate correlation between improving skin clearance and improved HRQoL, such that factors other than skin clearance may also impact HRQoL. Indeed, improvements in HRQoL are related to improvements in pain and itching, alongside improvements in skin clearance $[12,23]$. The

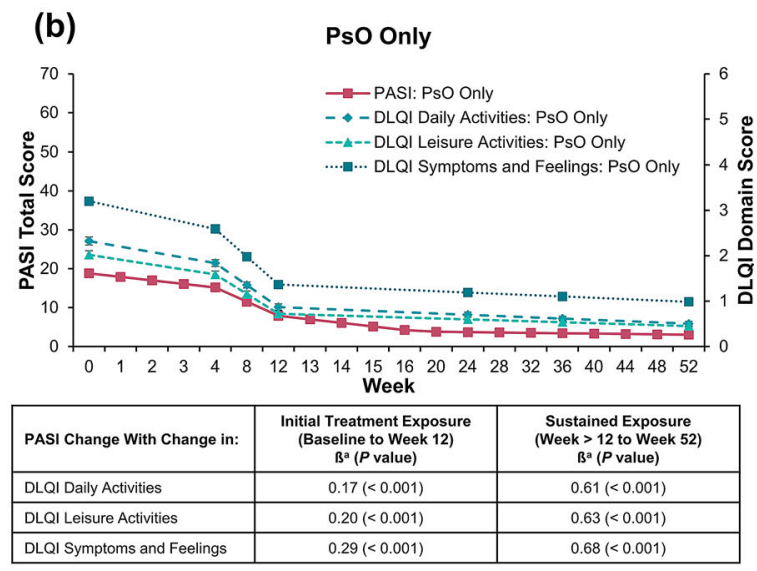

not explained by the included covariates) indicates that a change of 1 standardized value on the PASI will result in a change in a standardized value on the DLQI at the reported value (e.g. 0.20 for the initial treatment exposure on daily activities for the total population)

extent of skin clearance also dictates the relationship with HRQoL: patients who achieve complete skin clearance have greater HRQoL improvements [11, 24-28]. Within our study, skin clearance and HRQoL were correlated during the sustained response period, in which patients had PASI scores indicative of near complete skin clearance. Furthermore, greater skin clearance was associated with greater treatment satisfaction, and patients who discontinued treatment after initial optimal responses experienced disease flare and QoL decrements $[29,30]$. Therefore, it is important for clinicians and patients to maintain 
(a)

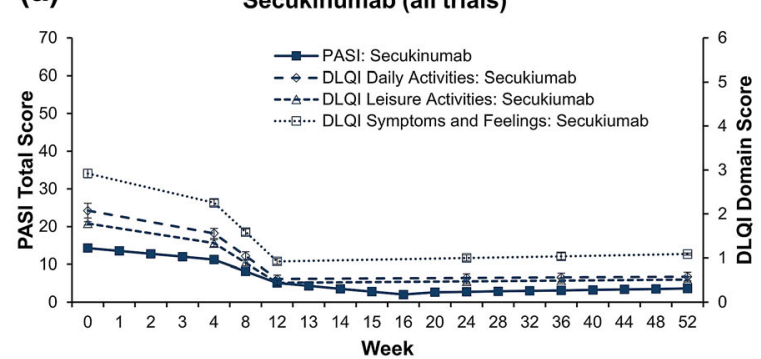

Week

\begin{tabular}{|l|c|c|}
\hline PASI Change With Change in: & $\begin{array}{c}\text { Initial Treatment Effect } \\
\text { (Baseline to Week 12) } \\
\boldsymbol{\beta}^{\mathrm{a}}(\boldsymbol{P} \text { value) }\end{array}$ & $\begin{array}{c}\text { Sustained Effect } \\
\text { (Week }>\text { 12 to Week 52) } \\
\boldsymbol{\beta}^{\mathbf{a}}(\boldsymbol{P} \text { value) }\end{array}$ \\
\hline DLQI Daily Activities & $0.25(<0.001)$ & $0.43(<0.001)$ \\
\hline DLQI Leisure Activities & $0.23(<0.001)$ & $0.44(<0.001)$ \\
\hline DLQI Symptoms and Feelings & $0.38(<0.001)$ & $0.50(<0.001)$ \\
\hline
\end{tabular}

(c) Placebo (nonresponders re-randomized to

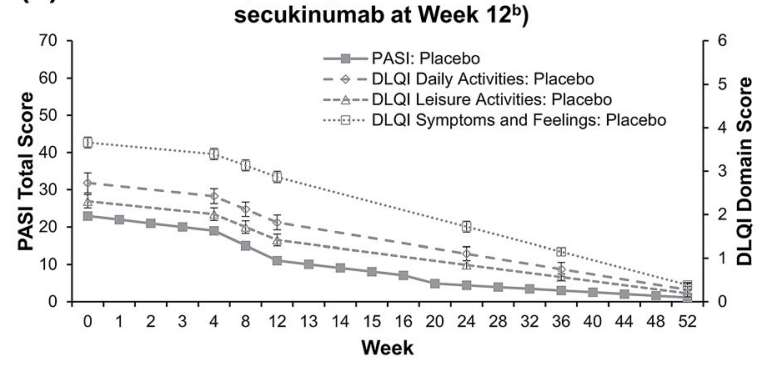

\begin{tabular}{|l|c|c|}
\hline PASI Change With Change in: & $\begin{array}{c}\text { Initial Treatment Effect } \\
\text { (Baseline to Week 12) } \\
\boldsymbol{\beta}^{\mathrm{a}}(\boldsymbol{P} \text { value) }\end{array}$ & $\begin{array}{c}\text { Sustained Effect } \\
\text { (Week }>12 \text { to Week 52) } \\
\boldsymbol{\beta}^{\mathbf{a}}(\boldsymbol{P} \text { value })\end{array}$ \\
\hline DLQI Daily Activities & $0.31(=0.550)$ & $0.37(<0.001)$ \\
\hline DLQI Leisure Activities & $0.42(<0.001)$ & $0.41(<0.001)$ \\
\hline DLQI Symptoms and Feelings & $0.35(=0.004)$ & $0.45(<0.001)$ \\
\hline
\end{tabular}

Fig. 3 Correlation of change in PASI score with DLQI domains in patients with $\mathrm{PsO}$ receiving a secukinumab, b etanercept, or c placebo. DLQI, Dermatology Life Quality Index; PASI, Psoriasis Area and Severity Index; $\mathrm{PsO}$, psoriasis. ${ }^{\mathrm{a}} \beta$ (standardized residual covariance: i.e. the correlation between the slopes not explained by the included covariates) indicates that a change of 1

treatment routines to ensure sustained and consistent clearance of skin. However, when complete skin clearance is not possible, clinicians should manage pain and itching, while monitoring other manifestations of disease or comorbidities, to improve QoL for patients.

The presence of comorbid PsA is associated with greater decrements in HRQoL than PsO alone, with a greater impact of itching, irritation, pain, and joint symptoms [6, 31-36]. Patients with comorbid PsA tend to have longer disease duration, are older, and are more likely to be female compared with patients with PsO only [31]; this was also observed in our patient

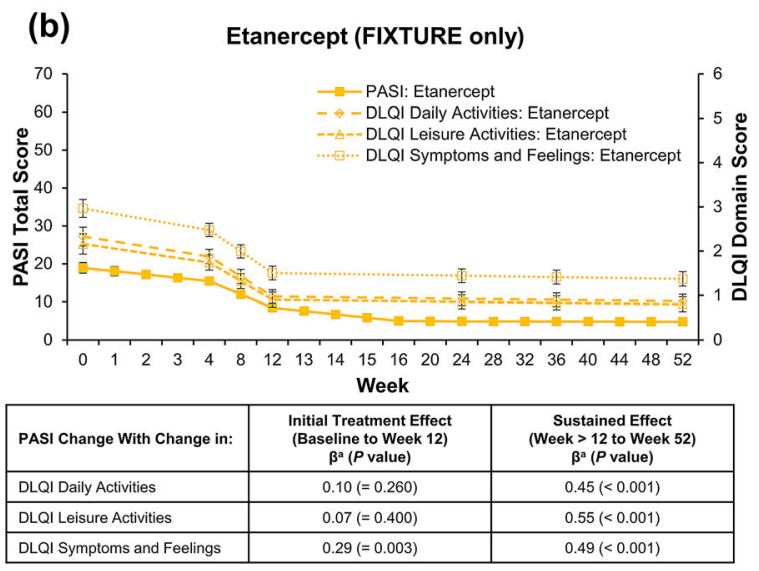

standardized value on the PASI will result in a change in a standardized value on the DLQI at the reported value (e.g. 0.25 for the initial treatment exposure of secukinumab on daily activities). ${ }^{\mathrm{b}}$ Patients who did not achieve PASI75 at week 12 were re-randomized 1:1 to receive secukinumab $300-150 \mathrm{mg}$

population who was treated with biologic treatments approved for both PsO and PsA. The correlation between changes in skin clearance and changes in HRQoL among patients with comorbid PsA was similar to that among patients with PsO only. Any additional burden of comorbid PsA did not change the association between improvements in skin clearance and improvements in HRQoL in this study cohort, although the underlying treatments may have alleviated several symptoms of PsA, countering any negative impact. The improvement in PsA clinical symptoms and their impact on HRQoL were not assessed in this study; however, it has 
been shown that successful treatment of both skin and joint symptoms in patients with PsA contributes more to improved HRQoL than either skin or joint symptoms alone, as assessed by PASI and Disease Activity Index for Psoriatic Arthritis [37]. Thus, treatment goals of improving skin clearance while managing the additional burden of itching, irritation, and pain associated with PsA will likely lead to improved QoL.

As previously documented, achieving complete or almost complete skin clearance has strong associations with HRQoL [11, 23-28]. Of interest for the present study was whether this sustained level of skin clearance was associated with an equally sustained level of HRQoL. In other words, do patients continue to perceive an improved level of HRQoL once their skin clearance has reached a certain threshold and no longer improves? The moderate-to-strong correlation between the PASI and DLQI scores during the sustained effect period suggests that as long as the level of skin clearance was maintained, HRQoL was also maintained.

Data were derived from randomized clinical trials investigating the safety and efficacy of secukinumab in which randomized patients were selected on the basis of strict eligibility criteria; thus, the results may not be generalizable to all patients with PsO. Additionally, the analysis lacked assessment of the impact of joint-related symptoms associated with PsA on HRQoL. Furthermore, analyses were limited to data that were collected within the clinical trials, and areas of special interest that significantly affect quality of life (e.g. nail psoriasis, scalp psoriasis, and genital psoriasis) were not specifically analysed in this study. The analyses were of trial results of extremely effective treatments, and a less effective treatment that resulted in smaller changes might not show such close correlations. The sample size for the etanercept arm was much smaller than those for the secukinumab and placebo arms; thus, caution is recommended when interpreting the results of the treatment-specific models.

\section{CONCLUSION}

Psoriasis severity (as measured by PASI) and disease-specific QoL (as measured by DLQI) are correlated among patients with moderate-tosevere PsO. Patients who experience improvements in skin severity are likely to also experience improvements in QoL. Similarly, once skin severity no longer improves, QoL is likely to remain stable. In other words, patients do not report a worsening in QoL if their skin severity remains stable. This was observed regardless of the presence of comorbid PsA if it was actively treated. These findings provide support for clinicians that improving skin clearance is likely to lead to better disease-specific QoL.

\section{ACKNOWLEDGEMENTS}

Funding. This study was sponsored by Novartis Pharmaceuticals Corporation, East Hanover, NJ. Support for third-party writing assistance and the Rapid Service Fee were funded by Novartis Pharmaceuticals Corporation, East Hanover, NJ.

Authorship. All named authors meet the International Committee of Medical Journal Editors (ICMJE) criteria for authorship for this article, take responsibility for the integrity of the work as a whole, and have given their approval for this version to be published.

Authors' Contributions. All authors made substantial contributions to the conception and methodology of the literature review, were involved in drafting and critically revising the work, take full responsibility for and ensure the integrity of the work, and have read and approved all versions of this manuscript.

Medical Writing, Editorial, and Other Assistance. Support for third-party writing assistance for this manuscript, furnished by Meaghan Paganelli, PhD, and Eric Deutsch, PhD, CMPP, of Health Interactions, Inc, was provided by Novartis Pharmaceuticals Corporation, East Hanover, NJ. 
Disclosures. Katherine Houghton is an employee of RTI Health Solutions. Dhaval Patil is an employee of Novartis Pharmaceuticals Corporation. Braulio Gomez was an employee of Novartis Pharmaceuticals Corporation at the time of this analysis and is currently an employee of UCB. Steven R. Feldman has received consulting, speaking, and/or research support from Novartis, AbbVie, Celgene, Sun Pharma, Janssen, Lilly, and Ortho.

Data Availability. All data generated or analyzed during this study are included in this published article.

Compliance with Ethics Guidelines. The previously conducted individual study protocols were approved by institutional review boards or ethics committees at all investigational sites. These studies were conducted in accordance with the ethical principles of the Declaration of Helsinki, and all US sites maintained compliance with Health Insurance Portability and Accountability Act regulations. All study subjects were required to provide written consent prior to participating.

Open Access. This article is licensed under a Creative Commons Attribution-NonCommercial 4.0 International License, which permits any non-commercial use, sharing, adaptation, distribution and reproduction in any medium or format, as long as you give appropriate credit to the original author(s) and the source, provide a link to the Creative Commons licence, and indicate if changes were made. The images or other third party material in this article are included in the article's Creative Commons licence, unless indicated otherwise in a credit line to the material. If material is not included in the article's Creative Commons licence and your intended use is not permitted by statutory regulation or exceeds the permitted use, you will need to obtain permission directly from the copyright holder. To view a copy of this licence, visit http://creativecommons.org/licenses/by$\mathrm{nc} / 4.0 /$.

\section{REFERENCES}

1. Langley RGB, Krueger GG, Griffiths CEC. Psoriasis: epidemiology, clinical features, and quality of life. Ann Rheum Dis. 2005;64(Suppl II):ii18-23. https:// doi.org/10.1136/ard.2004.033217.

2. Rachakonda TD, Schupp CW, Armstrong AW. Psoriasis prevalence among adults in the United States. J Am Acad Dermatol. 2014;70(3):512-6. https://doi. org/10.1016/j.jaad.2013.11.013.

3. Alinaghi F, Calov M, Kristensen LE, et al. Prevalence of psoriatic arthritis in patients with psoriasis: a systematic review and meta-analysis of observational and clinical studies. J Am Acad Dermatol. 2019;80(1):251-65.e219. https://doi.org/10.1016/j. jaad.2018.06.027.

4. Mease PJ, Gladman DD, Papp KA, et al. Prevalence of rheumatologist-diagnosed psoriatic arthritis in patients with psoriasis in European/North American dermatology clinics. J Am Acad Dermatol. 2013;69(5):729-35. https://doi.org/10.1016/j.jaad. 2013.07.023.

5. Kaushik SB, Lebwohl MG. Psoriasis: which therapy for which patient: psoriasis comorbidities and preferred systemic agents. J Am Acad Dermatol. 2019;80(1):27-40. https://doi.org/10.1016/j.jaad. 2018.06.057.

6. Lebwohl MG, Bachelez H, Barker J, et al. Patient perspectives in the management of psoriasis: results from the population-based Multinational Assessment of Psoriasis and Psoriatic Arthritis Survey. J Am Acad Dermatol. 2014;70(5):871-81. https:// doi.org/10.1016/j.jaad.2013.12.018.

7. Bhosle MJ, Kulkarni A, Feldman SR, Balkrishnan R. Quality of life in patients with psoriasis. Health Qual Life Outcomes. 2006;4:35.

8. Menter A, Strober BE, Kaplan DH, et al. Joint AADNPF guidelines of care for the management and treatment of psoriasis with biologics. J Am Acad Dermatol. 2019;80(4):1029-72. https://doi.org/10. 1016/j.jaad.2018.11.057.

9. Frieder J, Kivelevitch D, Fiore CT, Saad S, Menter A. The impact of biologic agents on health-related quality of life outcomes in patients with psoriasis. Expert Rev Clin Immunol. 2018;14(1):1-19. https:// doi.org/10.1080/1744666X.2018.1401468.

10. Chaptini C, Quinn S, Marshman G. Durable dermatology life quality index improvements in patients on biologics associated with psoriasis areas and severity index: a longitudinal study. Australas J Dermatol. 2016;57(3):e72-5. https://doi.org/10. 1111/ajd.12353. 
11. Puig L, Thom H, Mollon P, Tian H, Ramakrishna GS. Clear or almost clear skin improves the quality of life in patients with moderate-to-severe psoriasis: a systematic review and meta-analysis. J Eur Acad Dermatol Venereol. 2017;31(2):213-20. https://doi. org/10.1111/jdv.14007.

12. Stull DE, Griffiths CEM, Gilloteau I, et al. Differential effects of secukinumab vs. ustekinumab for treatment of psoriasis on quality of life, work productivity and activity impairment: a structural equation modelling analysis. $\mathrm{Br} \mathrm{J}$ Dermatol. 2018;178(6):1297-307. https://doi.org/10.1111/ bjd. 16366 .

13. Langley RG, Elewski BE, Lebwohl M, et al. Secukinumab in plaque psoriasis-results of two phase 3 trials. N Engl J Med. 2014;371(4):326-38. https:// doi.org/10.1056/NEJMoa1314258.

14. Blauvelt A, Prinz JC, Gottlieb AB, et al. Secukinumab administration by pre-filled syringe: efficacy, safety and usability results from a randomized controlled trial in psoriasis (FEATURE). Br J Dermatol. 2015;172(2):484-93. https://doi.org/10. 1111/bjd.13348.

15. Paul C, Lacour JP, Tedremets L, et al. Efficacy, safety and usability of secukinumab administration by autoinjector/pen in psoriasis: a randomized, controlled trial (JUNCTURE). J Eur Acad Dermatol Venereol. 2015;29(6):1082-90. https://doi.org/10. $1111 / j d v .12751$.

16. Finlay AY, Khan GK. Dermatology Life Quality Index (DLQI)-a simple practical measure for routine clinical use. Clin Exp Dermatol. 1994;19(3): 210-6.

17. Pariser D, Frankel E, Schlessinger J, et al. Efficacy of secukinumab in the treatment of moderate to severe plaque psoriasis in the North American subgroup of patients: pooled analysis of four phase 3 studies. Dermatol Ther (Heidelb). 2018;8(1):17-32. https://doi.org/10.1007/s13555-017-0211-4.

18. Pinter A, Gerdes S, Papavassilis C, Reinhardt M. Characterization of responder groups to secukinumab treatment in moderate to severe plaque psoriasis. J Dermatolog Treat. 2020;31(8):769-75. https://doi.org/10.1080/09546634.2019.1626973.

19. Umezawa Y, Saeki H, Nakagawa H. Some clinical factors affecting quality of the response to ustekinumab for psoriasis. J Dermatol. 2014;41(8):690-6. https://doi.org/10.1111/1346-8138.12538.

20. Hwang YJ, Youn SW, Kim BR, et al. Clinical factors predicting the therapeutic response to ustekinumab in patients with moderate to severe chronic plaque psoriasis. J Dermatol. 2017;44(5):560-6. https://doi. org/10.1111/1346-8138.13681.
21. Edson-Heredia E, Sterling KL, Alatorre CI, et al. Heterogeneity of response to biologic treatment: perspective for psoriasis. J Invest Dermatol. 2014;134(1):18-23. https://doi.org/10.1038/jid. 2013.326.

22. The bmj. 11. Correlation and regression, 2019. https://www.bmj.com/about-bmj/resourcesreaders/publications/statistics-square-one/11correlation-and-regression. Accessed April 9, 2021.

23. Lanna C, Galluzzi C, Zangrilli A, Bavetta M, Bianchi $\mathrm{L}$, Campione E. Psoriasis in difficult to treat areas: treatment role in improving health-related quality of life and perception of the disease stigma. J Dermatolog Treat. https://doi.org/10.1080/09546634. 2020.1770175 .

24. Augustin M, Dauden E, Mrowietz U, et al. Secukinumab treatment leads to normalization of quality of life and disease symptoms in psoriasis patients with or without prior systemic psoriasis therapy: the PROSE study results. J Eur Acad Dermatol Venereol. 2021;35(2):431-40. https://doi.org/10. $1111 / j d v .16632$.

25. Mattei PL, Corey KC, Kimball AB. Psoriasis Area Severity Index (PASI) and the Dermatology Life Quality Index (DLQI): the correlation between disease severity and psychological burden in patients treated with biological therapies. J Eur Acad Dermatol Venereol. 2014;28(3):333-7. https://doi.org/ $10.1111 / j d v .12106$.

26. Romiti R, Fabrício LHZ, Souza CDS, et al. Assessment of psoriasis severity in Brazilian patients with chronic plaque psoriasis attending outpatient clinics: a multicenter, population-based cross-sectional study (APPISOT). J Dermatolog Treat. 2018;29(8): 775-85. https://doi.org/10.1080/09546634.2018. 1466023.

27. Strober B, Papp KA, Lebwohl M, et al. Clinical meaningfulness of complete skin clearance in psoriasis. J Am Acad Dermatol. 2016;75(1):77-82.e77. https://doi.org/10.1016/j.jaad.2016.03.026.

28. Blauvelt A, Wu JJ, Armstrong A, Menter A, Liu C, Jacobson A. Importance of complete skin clearance in psoriasis as a treatment goal: implications for patient-reported outcomes. J Drugs Dermatol. 2020;19(5):487-92.

29. Strober BE, van der Walt JM, Armstrong AW, et al. Clinical goals and barriers to effective psoriasis care. Dermatol Ther (Heidelb). 2019;9(1):5-18. https:// doi.org/10.1007/s13555-018-0279-5.

30. Feldman SR, Bushnell DM, Klekotka PA, et al. Differences in psoriasis signs and symptom severity between patients with clear and almost clear skin in clinical practice. J Dermatolog Treat. 2016;27(3): 
224-7. https://doi.org/10.3109/09546634.2015. 1093589.

31. Edson-Heredia E, Zhu B, Guo J, Maeda-Chubachi T, Lebwohl M. Disease burden and quality of life in psoriasis patients with and without comorbid psoriatic arthritis: results from National Psoriasis Foundation panel surveys. Cutis. 2015;95(3):173-8.

32. Armstrong AW, Schupp C, Wu J, Bebo B. Quality of life and work productivity impairment among psoriasis patients: findings from the National Psoriasis Foundation survey data 2003-2011. PLoS One. 2012;7(12):e52935.

33. Daudén E, Pujol RM, Sánchez-Carazo JL, et al. Demographic characteristics and health-related quality of life of patients with moderate-to-severe psoriasis: the VACAP study. Actas Dermosifiliogr. 2013;104(9):807-14. https://doi.org/10.1016/j.ad. 2013.03.005.

34. Duvetorp A, Østergaard M, Skov L, et al. Quality of life and contact with healthcare systems among patients with psoriasis and psoriatic arthritis: results from the NORdic PAtient survey of Psoriasis and Psoriatic arthritis (NORPAPP). Arch Dermatol Res. 2019;311(5):351-60. https://doi.org/10.1007/ s00403-019-01906-z.

35. Obradors $M$, Blanch $C$, Comellas M, Figueras $M$, Lizan L. Health-related quality of life in patients with psoriasis: a systematic review of the European literature. Qual Life Res. 2016;25(11):2739-54. https://doi.org/10.1007/s11136-016-1321-7.

36. Rosen CF, Mussani F, Chandran V, Eder L, Thavaneswaran A, Gladman DD. Patients with psoriatic arthritis have worse quality of life than those with psoriasis alone. Rheumatol (Oxford). 2011;51(3): 571-6. https://doi.org/10.1093/rheumatology/ ker365.

37. Kavanaugh A, Gottlieb A, Morita A, et al. The contribution of joint and skin improvements to the health-related quality of life of patients with psoriatic arthritis: a post hoc analysis of two randomised controlled studies. Ann Rheum Dis. 2019;78(9): 1215-9. https://doi.org/10.1136/annrheumdis2018-215003. 